\title{
Atualidades/Actualities
}

\section{IMPLEMENTAÇÃO DE AÇÕES DE VIGILÂNCIA EPIDEMIOLÓGICA EM NÍVEL REGIONAL*}

\author{
Tânia Cristina de Oliveira**
}

\begin{abstract}
OLIVEIRA, T.C. de Implementação de ações de vigilância epidemiológica em nível regional. Rev. Saúde públ., S. Paulo, 23:79-81, 1989.

RESUMO: Relata-se experiência de reorganização dos serviços de Vigilância Epidemiológica, em nível regional, no Centro Regional de Saúde de Governador Valadares, MG, Brasil, durante o ano de 1985, com o objetivo de propor algumas medidas que possam contribuir para o aumento da remessa de informações pelo nível local.
\end{abstract}

DESCRITORES: Vigilância epidemiológica. Regionalização. Notificação de doenças, normas.

\section{INTRODUÇÃO}

O trabalho de Vigilância Epidemiológica (VE) regional freqüentemente tem sido associado ao simples recebimento e consolidação dos dados provenientes de nível local e passagem dos mesmos ao nível central, sem análise crítica ou preocupação com a devolução dos dados à base do sistema, usualmente criticada pela baixa motivação para as açðes de VE e para a remessa de informações regulares - aqui entendidas como a remessa de dados por mais de três semanas ao mês. A importância da informação regular para a organização das atividades de controle das doenças transmissiveis tem sido abordada em vários trabalhos ${ }^{1,5,6}$; contudo não foi observada a discussão dos problemas encontrados no dia-a-dia. O presente trabalho pretende discutir essas dificuldades, relatando a experiência ocorrida durante o ano de 1985 , no Centro Regional de Saúde de Governador Valadares - MG (CRS-GV), e propor algumas medidas simples que possam auxiliar o aumento da remessa de informaçס̃es pelo nível local e sua mobilização para as atividades de VE, permitindo assim melhorar as açðes de controle das doenças transmissíveis, tanto a nível local quanto regional e central.

\section{CARACTERISTICAS DO CENTRO E PROGRAMA DE} VIGILÂNCIA EPIDEMILÓGICA

A região de Governador Valadares, situada ao leste do Estado de Minas Gerais, com uma população de aproximadamente $800 \mathrm{mil} \mathrm{habi-}$ tantes, distribuídos por 53 municípios, apresenta um padrão de morbidade representado basicamente por doenças carenciais e verminoses (principalmente esquistossomose), tendo como município polo Governador Valadares ( $240 \mathrm{mil}$ hab.). No tocante à assistência médica, há um centro de saúde da Secretaria de Estado da Saúde de Minas Gerais (SES-MG) em cada um dos municípios da área e em pelo menos $40 \%$ deles um hospital de pequeno porte cuja referência é o Hospital Regional de Governador Valadares. Nesse município há ainda 7 centros de saúde, 2 hospitais privados e o Centro Regional de Saúde de Governador Valadares, cuja equipe, composta por 10 técnicos de nível superior, de diversas áreas de formação, supervisiona a rede básica dos municípios da área de abrangência do CRS-GV, ficando a cargo de cada um dos técnicos da equipe um dos programas da SES-MG. O Programa de Vigilância Epidemiológica (PVE), assim como o Programa de Saúde Oral ficavam, até novembro de 1984, sob a

* Trabalho apresentado no I Congresso Brasileiro de Saúde Coletiva, Rio de Janeiro, 1986.

** Secretaria de Estado da Saúde de São Paulo - SUDS R-28 - Rua Paissandu, 11 - 13800 - Mogi-Mirim, SP - Brasil. 
supervisão de um odontólogo, que não havia recebido treinamento específico para tal atividade. Em dezembro de 1984 foi contratada uma médica sanitarista para assumir a coordenação do PVE/CRS-GV, passando a atuar conjuntamente com a enfermeira responsável pelo Programa de Imunizações. Naquela época as ações do PVE se limitavam à investigação esporádica de casos e surtos de doenças transmissíveis, sendo a média anual de municípios, com notificação regular, de $42,7 \%$ em 1984 , não havendo avaliação das ações realizadas e nem mesmo programação ordenada das atividades a serem desenvolvidas.

Nossas ações iniciaram-se por uma definição clara do universo a ser trabalhado, com ampliação para 25 da lista de 7 doenças notificáveis. Esta lista, acompanhada do calendário de semanas epidemiológicas, foi intensamente divulgada nas unidades e centros de saúde da área, assim como nos hospitais dos municípios, sendo afixada nas salas de registros, postos de enfermagem e mesas de consultórios médicos.

O Boletim de Notificação Semanal, enviado semanalmente pela rede ao CRS-GV, sofreu modificações, com ampliação das informações ali contidas, passando a ser impresso e aerogramas, evitando-se a utilização de selos, na expectativa de garantir o envio das informações. Foi instituído o sistema de ligações telefônicas a cobrar para o informe das doenças de notificação rápida e esclarecimento de dúvidas relativas às açōes de VE. Foram também realizados contatos com a rede hospitalar pública e privada do município de Governador Valadares para esclarecimento da importância da notificação regular.

Durante $o$ ano foram convidados para treinamento todos os médicos (55) e enfermeiras (3) de nível local, divididos em 6 turmas, que se ausentavam de suas funções durante dois dias e meio, vindo à sede do CRS-GV com diárias pagas pela SES-MG. O índice de ausências foi de $7 \%$, tendo sido remetido o material do curso aos faltosos. Foi utilizado para treinamento o Curso de Introdução à Vigilância Epidemiológica (CIVE) ${ }^{2}$, elaborado pelo Ministério da Saúde, composto de 9 casos clínicos típicos de doenças imunizáveis a serem discutidos em grupo, acompanhados da discussão de algumas questões relativas à VE dessas doenças. Acrescentou-se a este material o módulo da rede de frio do Curso do Programa Ampliado de Imunizações, elaborado pela $\mathrm{OPAS}^{4}$ e uma discussão sobre o Sistema Nacional de Vigilância Epidemiológica ${ }^{3}$, mostrando o caminho seguido pela informação enviada pelo nível local. Além disso, o CIVE permitiu não somente um conta- to mais estreito com os médicos e enfermeiras da rede como a apresentação de uma visão mais abrangente da importância da retroalimentação do sistema para o conhecimento e intervenção no quadro mórbido da região e dos municípios.

Completando nossas ações, foi elaborado um Boletim Informativo do PVE do CRS-GV, com periodicidade trimestral e enviado aos hospitais e à rede básica da área de abrangência do CRS-GV. O objetivo de tal boletim era devolver sucintamente os dados coletados a nível regional, de tal forma que se pudesse ter uma idéia das ações que vinham sendo desenvolvidas pelo CRS-GV a partir da informação recebida, estimulando assim o envio regular das notificações. Além disso, incluímos dados sobre a cobertura vacinal dos municípios de abrangência do CRS-GV.

\section{COMENTÁRIOS}

Como resultado das ações implementadas, o indice de municípios com notificação regular passou de $47,2 \%$ em janeiro para $100 \%$ em dezembro de 1985. O número médio de unidades hospitalares em notificação regular foi, naquele ano, de $76,5 \%$ contra $22,4 \%$ em 1984 .

Houve também um implemento global do PVE do CRS-GV por melhoria da possibilidade de análise da morbidade tanto a nível da região, como dos municípios, sendo mais freqüentes as ações de vigilância em nível local. Em um dos municípios foi reproduzido o treinamento para médicos e enfermeiras, sob a responsabilidade de um médico do Centro de Saúde local, treinado no CRS-GV.

A devolução de dados ao nível local, mesmo de forma simplificada, é essencial para a continuidade da remessa de informaçōes e motivação para as atividades de vigilância epidemiológica. No caso do CRS-GV, alguns fatores, como a dimensão da área de abrangência, o reduzido tamanho da equipe de supervisão, a ausência de treinamento específico para a coordenação do PVE, entre outros, dificultaram a organização eficiente da informação existente em nivel regional.

Acredita-se que os resultados conseguidos durante o ano de 1985, apesar da impossibilidade de comparação com os anos anteriores, por ausência de dados, podem ser associados a um conjunto de fatores, entre os quais:

- A integração entre os Programas de VE e de Imunização.

- Maior acessibilidade da coordenação do PVE para o nível local, que podia esclarecer 
a qualquer momento dúvidas relativas às açōes da VE, democratizando um saber técnico concentrado em nível regional, na busca do incentivo ao envio de informaçðes.
- O CIVE, embora de abrangência limitada, mostrou-se como alternativa viável para instrumentar a capacitação de pessoal de nível local para as ações de VE.

OLIVEIRA, T.C. de [The implementation of epidemiological surveillance actions at regional level]. Rev. Saúde públ., S. Paulo, 23:79-81, 1989.

ABSTRACT: An attempt at a reorganization of the Epidemiological Surveillance Service at regional level in the Central Health Region of Governador Valadares, MG, Brasil, undertaken during 1985 is reported on. This study discusses simple measures that may be taken with a view to increasing interest in Epidemiological Surveillance actions at the local level and emphasizes the fact that the of data to the local level is essential to this interest.

KEYWORDS: Population surveillance. Regional health planning. Disease notification, standards.

\section{REFERÊNCIAS BIBLIOGRÁFICAS}

1. FUNDAÇÃO SERVIÇOS DE SAÚdE PÚBLICA. Sistema Nacional de Vigilância Epidemiológica: projeto para o desenvolvimento de vigilância epidemiológica em nível nacional. Rio de Janeiro, 1974. [Mimeografadol

2. MINISTÉRIO DA SAÚDE. Curso de introdução à vigilância epidemiológica. Brasília, 1982. [Mimeografado]

3. MINISTÉRIO DA SAÚDE. Sistema Nacional de Controle de Doenças Transmissíveis. Brasília, 1983. [Mimeografado]

4. ORGANIZAÇÃO PANAMERICANA DA SAÚDE.
Controle das doenças da população. Washington, D.C., s.d. (ENSP/doc. 1517). [Mimeografado]

5. ORGANIZAÇĀO MUNDIAL DA SAÚDE. O conceito de vigilância epidemiológica. Washington, D.C., 1969. [Mimeografado]

6. ROMERO, A. \& TRONCOSO, M.C. La vigilancia epidemiológica: significado e implicaciones en la practica e en la docencia. Cuad. med. soc., Rosario, 17:17-28, 1981.

Recebido para publicação em 28/1/1988. Reapresentado em 26/8/1988.

Aprovado para publicação em 1/9/1988. 